\title{
Formación de un sistema productivo: los enclaves forestales de la región chaqueño-misionera (Siglos XIX-XX)
}

por

Ruben E. Bitlloch y Horacio Sormani

\begin{abstract}
El propósito de este trabajo es el de describir el proceso de desarrollo de una forma de organización de la producción que, teniendo como núcleo al obraje maderero-yerbatero y al aserradero-fábrica de tanino, tuvo lugar durante las últimas décadas del siglo XIX y la primera mitad del siglo XX en el nordeste Argentino. La denominación de enclave que le adjudicamos a estos núcleos de actividad posee un significado espacial y socio-económico ya que se caracterizaron por establecer una suerte de aislamiento físico o clausura espacial. Estos enclaves se explayaron espacialmente en un área recientemente apropiada a las comunidades indigenas configurando un dominio territorial al cual le fueron otorgando cierta configuración que fue cambiando al alterarse las condiciones en que se desenvolvía la forma de organización de la producción que le dio origen.

PALABRAS CLAVE: forma de organización de la producción; enclave; clausura espacial; dominio territorial.
\end{abstract}

\section{INTRODUCCIÓN}

El presente trabajo tiene un alcance limitado. No intenta someter a discusión el proceso global de una investigación realizada, sino más bien analizar algunos de sus aspectos metodológicos más relevantes y debatir algunas de sus conclusiones. La investigación tiene por objeto describir el proceso formativo de una forma de organización de la producción que, teniendo como núcleo al obraje maderero/yerbatero y al aserradero/fábrica de tanino, tuvo lugar durante las últimas décadas del siglo XIX y la primera mitad del siglo XX en la región chaqueño-misionera, en el nordeste de Argentina. 
La historiografía argentina mostró, por lo general, gran predilección por la forma de organización de la producción de la estancia pampeana. Las razones fueron por demás atendibles: esta logró cubrir un espacio territorial tan extenso y rico que incluyó, en los años de su mayor esplendor, a la mayor parte de la población nacional ${ }^{1}$. Al no verse originalmente entorpecida por barreras naturales, ni por la resistencia de formas precapitalistas que le limitaran o disputaran el acceso a la tierra, pudo ir ajustando los cambios en el uso del espacio, expandiéndose territorialmente sin necesidad de asimilar el costo de excesivos conflictos. Lo último, sin embargo, debe ser entendido y ubicado en su contexto histórico: el apogeo de la misma, a fines del siglo XIX, coincidió con el momento en que el llamado problema del indio ya había sido militarmente resuelto no solamente en la región de la Pampa, sino que también en Patagonia y, estaba en vías de serlo en otras zonas periféricas².

La producción de la pampa húmeda contribuyó a otorgar a la Argentina la imagen de una gran homogeneidad interna, o al menos aparentemente, facilitando así la precoz identificación de la región pampeana con el espacio nacional argentino y de sus terratenientes con la burguesía del país en su conjunto. Y ello cuando, paradójicamente, la diversidad regional estaba en la base de la historia nacional, tanto en términos humanos y socioeconómicos como institucionales. No puede uno extrañarse que, hasta cierto punto, también se identificara a la historia económica pampeana con la nacional, particularmente cuando las otras formas de organización de la producción se vieron tarde o temprano y directamente o indirectamente subordinadas a la pampeana.

La génesis de los enclaves forestales chaqueño-misioneros estuvo subordinada al desenvolvimiento de la estancia pampeana, lo que queda en evidencia si se analiza el proceso de apropiación y distribución de la tierra, la implantación de las redes ferroviarias y el cometido que desempeñó la región, parcialmente determinado por el funcionamiento de conjunto de la economía pampeana ${ }^{3}$. La revisión de ese proceso formativo, sin embargo, pone en evidencia la diversidad regional y la existencia de estructuras económicas que divergieron sustancialmente de las montadas por el capitalismo agrario pampeano en su inserción en la economía mundial ${ }^{4}$.

1 Véanse al respecto algunos trabajos clásicos, como: Díaz Alejandro, 1983; Cuccorese, 1971; Dorfman, 1942 y 1970; Gondra, 1943; Ortiz, 1978; Puiggros, 1948. 1994.

2 Véanse al respecto, entre otras obras: Walther, Juan Carlos, 1980; Ras, Norberto,

3 Ortiz, 1943 y 1958.

4 Rofman y Romero, 1974. 
Parece oportuno, entonces, retomar el estudio de ese proceso o, al menos lo parecía en los tramos iniciales de la investigación, como una manera de contribuir a hacer resaltar su originalidad, particularmente cuando ese proceso se caracterizó por un temprano predominio de la empresa capitalista que actuaba en un mercado oligopólico, circunstancia que no concuerda con las generalizaciones trazadas por extensión del modelo pampeano. Puede aún agregarse otra particularidad que refuerza la tipicidad de esta forma de organización de la producción: la ubicación de los establecimientos productivos en un área alejada de la sede de las decisiones directivas y administrativas, esquema que participa de los rasgos de otros espacios económicos escindidos, de los que la historia moderna y contemporánea proporciona interesantes ejemplos, tanto agrarios - plantaciones - como mineros, industriales o comerciales. Cabe recordar, al respecto, la distinción hecha por cierta historiografía entre formas de desarrollo localmente administradas y formas de tipo enclave, aplicable al caso que nos ocupa, pues la estancia pampeana se puede identificar con la primera categoría, mientras que la gran empresa forestal correspondería a la segunda 5 .

Empero debe hacerse aquí una distinción fundamental, la denominación de enclave que le adjudicamos a los núcleos productivos obrajes madereros/ yerbateros y a los aserraderos/fábricas de tanino chaqueños-misioneros, tiene un doble significado:

En primer lugar, en su forma madura, sobre todo, aparecen como núcleos de actividad primaria controlados en forma directa desde afuera del país. Tal es el caso de The Forestal, Land, Timber and Railways Company, Limited, más conocida como La Forestal, y de otras empresas forestales asentadas en la región chaqueño-misionera, cuyos accionistas, directorios y centros de decisión estaban localizados en el extranjero, adonde se remitían las utilidades que la compañía resolvía distribuir. Las fábricas de tanino más importantes de esa región habían sido construidas con capital europeo y funcionaban bajo supervisión administrativa, científica y técnica de europeos ${ }^{6}$. Otra de las características típicas era que su actividad generaba la existencia de pocos eslabonamientos regionales ya que las maquinarias eran totalmente importadas $\mathrm{y}$, por ejemplo, ciertos productos como la harina y el aceite, adquiridos para la alimentación de los trabajadores, se traían de otras regiones argentinas; solamente la carne y las fuentes de energía - leña - eran producidas internamente dentro de la misma unidad productiva. En términos generales, esos emplazamientos productivos constituían, en realidad, una extensión del espa-

\footnotetext{
5 Cardoso y Faletto, 1971.

6 Hoar, 1924: 1.
} 
cio económico de las economías centrales. La producción taninera, por ejemplo, estaba destinada prácticamente en su totalidad al comercio exterior, ya que la propia economía argentina absorbía menos del 10\% de la misma, por lo que la actividad productiva interna estaba condicionada por la demanda y el precio internacional y consecuentemente sometida a sus fluctuaciones y desequilibrios; con esta observación queremos señalar su integración en primer lugar al mercado mundial, más que al nacional.

En segundo lugar, el término enclave nos servirá para poner de manifiesto cierto aislamiento físico o clausura espacial, elemento característico de la empresa forestal activa en el medio chaqueño-misionero. Originalmente estuvo determinado por condiciones naturales, sociales e institucionales, como son: a) la presencia del bosque y sus habitantes aborígenes; b) la incertidumbre respecto, entre cosas, a la propiedad del recurso natural, a la facultad del capital extranjero de disponer de las utilidades obtenidas y, sobre todo, incertidumbre con relación a la disponibilidad de mano de obra, no solamente de gerentes y capataces, sino de trabajadores que debido a los arraigados hábitos ambulatorios, tanto de la población indígena como criolla, podía generar escasez de la misma.

\section{FORMA DE ORGANIZACIÓN DE LA PRODUCCIÓN}

Dado que en reiteradas oprtunidades hemos hecha referencia a esta noción, conviene ahora aportar algunas precisiones generales a la misma. Por forma de organización de la producción designamos un conjunto relativamente homogéneo de relaciones técnicas y sociales, localizado y asociado a un tipo específico de producción, sea este agrario, industrial, forestal, minero, etc., que responde a determinado patrón de división social y territorial del trabajo y que se inserta en un esquema económico más amplio, de cuyas caraterísticas constituye una especie particular, ubicada en el tiempo y en el espacio.

El entrelazamiento de una o más formas de organización de la producción con elementos superestructurales de diverso orden: etnohistóticos, políticos, lingüísticos, da lugar a la formación de las regiones y sirve para definir los rasgos dominantes de la estructura regional en cada etapa de su desarrollo. Por cuanto toda forma de organización de la producción se explaya espacialmente en un determinado dominio territorial, resulta que sus rasgos tienen que haber otorgado a ese ámbito una cierta estructura, una configuración particular que se hace evidente por la forma y disposición de los asentamientos humanos y las redes de interconexión, así como por el patrón de usos del espacio que puede ser evidenciable en cada caso. Dicho de otra manera, en 
cada etapa del desenvolvimiento de una sociedad o de parte de ella, y en cada porción de su dominio territorial, alguna forma de organización de la producción o, eventualmente, más de una, habrán sido responsables de la conformación espacial de ese territorio. Particularmente, se habrán puesto de manifiesto uno o más elementos ordenadores que coinciden usualmente con el núcleo elemental o núcleo típico de la forma de organización de la producción, aquel precisamente en el cual las relaciones básicas a ella inherentes se evidencian con mayor claridad y definición.

En nuestro caso, el obraje maderero/yerbatero, y después el aserradero/fábrica de tanino, que a veces abarcaba a los anteriores, se constituyeron en los núcleos típicos del enclave forestal y en los elementos ordenadores del espacio regional en la región chaqueño-misionera, incluyendo el propio del establemiento cuando este, por sus dimensiones, asumió el tamaño de una subregión dentro de la sociedad regional. Los casos de La Forestal y de Las Palmas del Chaco Austral, para mencionar a dos grandes empresas, son bien elocuentes al respecto.

Esos núcleos típicos, los centros elementales de la forma de organización de la producción no aparecen aislados, sino vinculados entre sí a través de redes de interconexión, configurando el espacio en que se desarrollará una gran parte de la historia regional. Si dejamos de lado el área ocupada actualmente por la provincia de Corrientes, cuya estructura económico-espacial fue generándose a partir de la colonización española y de la fundación de su capital, en 1588, el resto del área de estudio puede ser considerada como una tierra nueva. Esta región de aproximadamente 350.000 kilómetros cuadrados, equivalente a un cuadrado de casi 600 kilómetros de lado, que incluía las actuales provincias argentinas de Chaco, Formosa y Misiones, el norte de Santa Fe y las porciones orientales de Santiago de Estero y Salta, permaneció inconquistada durante el periodo colonial - las pocas reducciones que se instalaron en la misma tampoco perduraron - $\mathrm{y}$, solamente una parte de Misiones fue ocupada por las comunidades guaraníticas y guaranizadas organizadas por la Compañía de Jesús durante los siglos XVII y XVIII ${ }^{7}$. Recién durante el periodo republicano, y más concretamente a partir de 1880, tan vasto territorio fue ocupado por el ejécito argentino. Resulta, entonces, que la forma de organización de la producción que nos ocupa encontró su propia génesis en el mismo proceso de apropiación e incorporación de esa tierra nueva al espacio nacional argentino. Sus determinaciones, por así decirlo,

\footnotetext{
7 Véanse: Gullón Abao, 1993. Vitar, 1997. Saeger, 2000.
} 
actuaron sobre una materia prácticamente intacta. Esta originalidad, constituye un aspecto relevante que bien justifica estudiar el tema.

\section{PERIODIZACIÓN Y CARACTERIZACIÓN DE UN SISTEMA PRODUCTIVO}

Como ya hemos afirmado, la implantación de los enclaves forestales se produjo en tierras nuevas. El asentamiento temporario de núcleos de indígenas - reducciones - organizados por misioneros europeos y el corrimiento lento y en cierto modo gradual de la frontera con las etnias del Gran Chaco, debido a la extensión, particularmente, de los usos del espacio pecuario, sirvieron para limitar el ámbito territorial indígena, pero no lograron modificar sustancialmente el carácter general del área, ya que incluso durante ese conflicto secular, muchas veces se debieron abandonar tierras ocupadas ante la hostilidad de los indígenas chaqueños. Así este territorio permaneció prácticamente inalterado hasta producirse la conquista militar y la consiguiente ocupación de su espacio.

La expropiación de la tierra a las etnias chaqueñas y su apropiación, en primera instancia, por el Estado argentino, fue una condición esencial: implicó, al mismo tiempo, desposeer a aquellas de sus condiciones naturales de vida, pre-requisitos de su propia existencia y reproducción, y transferirlos a los nuevos dueños para que sirvieran de base a un nuevo modelo socio-económico.

Esta desafectación de los recursos naturales - la tierra y el bosque - de sus antiguos poseedores no se produjo de manera instantánea, sino a lo largo de un lapso relativamente largo. El emplazamiento de avanzadas y puestos fronterizos por parte de los primeros gobiernos nacionales no hizo más que sustituir el cerco de asentamientos religiosos y cívico-militares establecidos en la época colonial, y sirvieron para definir una franja de transición más o menos estable, por no decir fluctuante: la frontera, linde político y social que separaba las etnias chaqueñas de, en primer lugar, la sociedad colonial rioplatense y, más tarde, de la argentina. En la región chaqueño-misionera —al igual que en llanura pampeana- la frontera fue también zona de contacto, pues no impedía los desplazamientos de los grupos humanos ni el intercambio de productos, aunque frecuentemente era perturbada por intromisiones en uno y otro sentido, saldadas usualmente con el apoderamiento o el rescate de bienes y personas. Tenía un carácter difuso, porque los hábitos, los bienes y hasta los cometidos de los distintos grupos se intercambiaban con frecuencia, como lo testimonió el ingeniero Arturo Seelstrang, el que estimó que, hacia 1875, entre 1.500 y 2.000 individuos, los isleños, a los que calificó de vagos, eva- 
didos y desertores, estimulaban a los indígenas a asaltar asentamientos de colonos o eran, ellos mismos, culpables de saqueos o destrucciones, que posteriormente eran atribuidos a los aborígenes. Nació la frontera asociada al fortín, que representa su elemento espacial característico, el que era un precario asentamiento humano dependiente de la administración militar, sin base económica sólida, a pesar de la dualidad de sus ocupantes: soldados y productores, supeditados, además, en el periodo republicano, a los cambios de la política nacional ${ }^{8}$.

En ese contexto se ubica el enclave forestal primitivo, cuyo elemento espacial típico es el obraje maderero/yerbatero, que constituye el producto de un incipiente proceso de desarrollo económico. Estos enclaves tenían un carácter inestable e itinerante, determinado por la calidad, la estacionalidad y la densidad de los recursos forestales; la tala del bosque no implicaba la propiedad de la tierra y estaba solo condicionada por la precariedad de normas legales que bien podían no cumplirse. Eran explotaciones depredatorias que, en el lenguaje de la primitiva ganadería pampena, podrían haberse llamado una vaquería forestal:

La explotación de las maderas se efectúa de la manera siguiente: el empresario se establece con unos cuantos peones correntinos en el paraje que le ofrezca más comodidades, tanto por la cercanía de un río navegable, como por la abundancia de maderas en el monte. Por medio de regalos atrae a los indígenas y a su cacique, y compra el bosque que elige por un poncho de paño, un sombrero, una yegüa con cría y una docena de frascos de ginebra, según su tamaño e importancia de árboles. Efectuado el negocio se construyen ranchos provisorios, los mismos indios con amigables demostraciones se conchaban como peones y el trabajo principia. Los árboles elegidos se cortan y sus trozos son labrados en el monte, donde permanecen hasta que una numerosa tropa de carros y bueyes los conducen al puerto, al que aprovechando una creciente propicia llegan los buques, para cargarlos y transportarlos a Corrientes $\mathrm{u}$ otros puntos a que son destinados para ser comerciados o empleados en las construcciones. Tal es brevemente explicado el mecanismo de un obraje, que se traslada de un punto a otro tan luego escasean los buenos árboles en el paraje que ocupaba, para buscar otro en el que sean más abundantes ${ }^{9}$.

Estas actividades depredatorias, de individuos y compañías particulares que explotaban bosques no concedidos en propiedad — siendo común, además, que muchas concesiones de tierras recibidas para colonizar encubrían, en realidad, explotaciones de bosques - llevaron al gobierno nacional a sancionar un decreto sobre la explotación de los bosques nacionales, el 19 de abril de 1879, aprobado por Ley n. ${ }^{\circ} 1054$ del 9 de octubre de 1880, por el

\footnotetext{
8 Seelstrang, 1977: 18-19, 71-72, 95.

9 Ibidem: 67-68.
} 
cual se determinaba que los mismos no podían ser explotados sin la correspondiente concesión previa, otorgada por el ministerio del Interior.

El aislamiento de los obrajes de su entorno regional - propio de los enclaves - abiertos hacia la ciudad usualmente por una única vía: el río, y más tarde la línea ferroviaria, implicaba una restricción. En un informe elevado por el gobernador de Misiones en noviembre de 1913, se informaba que el personal contratado en la ciudad de Posadas, capital del territorio, recibía un anticipo y cuya cantidad no siempre se entregaba toda en efectivo, siendo común que la mitad consistiera en mercaderías compradas en la propia casa comercial del dueño de la explotación forestal. Los contratados - en su mayorías analfabetos - eran inmediatamente embarcados y trasladados a los obrajes madereros-yerbateros, no pudiendo volver si el empresario no lo autorizaba, ya que tres empresas de navegación, las de Domingo Barthe, Núñez y Gibaja y Juan B. Mola, controlaban el servicio de pasajeros y de carga en el Alto Paraná, trabajando estrechamente con los empresarios forestales y el regreso por tierra era imposible debido a la impenetrabilidad de la selva. El personal que había finalizado con su contrato de seis meses no era embarcado hasta que no hubieran cubierto, con el trabajo, la deuda contraída por la compra de ropas y/o alimentos en la proveeduría de la misma empresa, cuya contabilidad, llevada por la administración del establecimiento, no era controlada por ninguna autoridad pública ${ }^{10}$.

Caracteriza a los obrajes la falta de una determinación general de las condiciones de trabajo. La extensión de la jornada, los descansos, permisos, atención médica, se determinaban en cada uno de ellos, en términos que seguramente resultarán familiares, por su dureza, a quienes conozcan las formas laborables de similares establecimientos en muchas partes del mundo, previos a las reivindicaciones sindicales y a la formación de una conciencia social. Así, entre otros rasgos, la violencia solía imperar como forma de garantizar la seguridad y aplicar castigos a los infractores a las normas establecidas por las propias empresas forestales ${ }^{11}$.

Por otra parte las grandes empresas creaban su propio excedente de mano de obra, ya que la explotación forestal se caracterizaba por periodos de gran expansión seguidos por periodos de receso. La tendencia que predominaba en ellas era la de obtener, lo más fácilmente y rápidamente posible, excepcionales ganancias. Además, la falta de entidades sindicales que exigieran mejoras en las condiciones de vida y de trabajo determinaba la existencia de un mer-

10 Niklison, 26 (Buenos Aires, 30 de abril de 1914): 63. Unsain, 26 (Buenos Aires, 1914): 5.

11 Bialet-Massé, 1968: 53-88. Isabello de Onís, XVIII/228 (Buenos Aires, 1986): 55-65. 
cado regional con bajos niveles de consumo no cumpliendo ningún rol dinámico en el desarrollo económico. Por otro lado, si nos atenemos a los documentos de la época, encontramos excepciones al funcionamiento descrito, como lo indicaba el inspector laboral José Elías Niklison, que se refirió a la Sociedad Anónima Quebrachales Fusionados, como la mejor que había visitado:

[...] y si no existieran en ella los intermediarios de siempre, en los trabajos del obraje - los contratistas - podría afirmarse, de manera absoluta, que el obrero goza en ella de completa libertad y de excelente trato por parte de sus patrones ${ }^{12}$.

La Sociedad Anónima Quebrachales Fusionados fue formada en 1906, por la fusión de La Industrial del Chaco, El Tanino de Puerto Max y El Quebracho de Puerto María. La nueva empresa, con un capital de 7.000.000 de pesos, tenía su sede en Buenos Aires y sus estatutos fueron aprobados por el gobierno argentino el 31 de mayo de 1906. La fusión se realizó en vista de las ganancias obtenidas por La Industrial del Chaco - cuya fábrica de tanino estaba ubicada en Puerto Tirol - lo que le permitió acordar un dividendo del $88 \%$ a los accionistas y en la creencia de que se lograría un éxito similar con las fábricas de las otras dos empresas ubicadas en la República del Paraguay. La compañía redujo su capital a 1.700 .000 pesos, concentrando sus actividades industriales en los establecimientos de Puerto Tirol, aserradero y fábrica de tanino, donde se producían extracto de quebracho -650 toneladas mensuales - , durmientes, postes y aserrín para curtiembres; unos 400 hacheros trabajaban en las tareas forestales, mientras que otros 250 trabajadores se dedicaban a la producción de tanino. Tanto el aserradero como la fábrica y los montes que explotaba en Colonia Lucinda, en territorio argentino, estaban situados en tierras de propiedad de Quebrachales Fusionados, la que tenía en su conjunto una superficie aproximada de 40.000 hectáreas. Las propiedades en Puerto Max, situadas en el Chaco paraguayo, alcanzaban a unas 45.000 hectáreas, y 500 personas trabajaban en la misma. La superficie de Puerto María era la más grande, con 168.750 hectáreas. En la proveeduría se vendían los productos a los precios corrientes en el Chaco, pero no se alteraban las medidas en beneficio propio. El ferrocarril tenía una extensión de 80 kilómetros de vías: un ramal lo empalmaba con el Ferrocarril Rural de Resistencia, vinculándolo a dicha ciudad y al inmediato puerto de Barranqueras, y el otro ramal lo comunicaba con el Ferrocarril de la Provincia de Santa Fe. Pero Quebrachales Fusionados no pudo posteriormente

\footnotetext{
12 Niklison, 32 (Buenos Aires, 31 de julio de 1915): 55.
} 
afrontar la competencia de La Forestal, siendo adquirida por esta última compañía en $1933^{13}$.

\section{LAS VARIANTES HISTÓRICAS DE LOS OBRAJES}

El primitivismo de las formas de organización y explotación de los obrajes no debe entenderse como inherente a formas pre-capitalistas, sino que era producto de las sencillas técnicas que se necesitaban aplicar, del entorno agreste y de la lejanía y aislamiento de la región. Por su débil contribución al desarrollo regional casi no han dejado huellas actualmente discernibles, como no sean los recuerdos de personas, circunstancias y lugares, conservados en la tradición oral.

Dentro de la forma obraje reconocemos algunas variantes históricas. Estaban como antecedentes lejanos los obrajes primitivos de la frontera, cuyos rastros se pierden en el pasado colonial de la región chaqueño-misionera, los cuales reaparecieron en forma más moderna tras la firma de un tratado de paz el 9 de octubre de 1824, en el paraje del Rubio, entre las autoridades de la provincia de Corrientes y los indios abipones del Chaco. A cambio de la paz, los indígenas recibieron dinero, géneros, vacas, ovejas y caballos, acordándose, además, el rescate de cautivos, y declarándose libre el comercio — con excepción de pólvora, ganado vacuno y caballar - entre los indígenas abipones y los habitantes de Corrientes. El tratado fue cumplido y permitió el establecimiento de obrajes en la costa occidental del río Paraná, los que progresaron incesantemente en los años posteriores; lo que marcó el inicio de la frontera chaqueña del periodo republicano: un territorio solo parcialmente ocupado, hasta cierto punto neutral y conflictivo, ya que en 1834, por ejemplo, indígenas tobas asaltaron los obrajes madereros instalados en el territorio del Chaco $^{14}$.

Los años de la Confederación Argentina y los inmediatamente posteriores, especialmente a partir de 1862, vieron el desarrollo de la segunda variante histórica del obraje. En esa época tomó impulso la construcción de subestructuras económicas destinadas a consolidar e integrar las redes de interconexión, aumentando la demanda de elementos estructurales para puentes, muelles, vías ferroviarias. Hacia fines de la década de 1860, le expansión agrícola pampea-

13 Lloyd, 1911: 429-430. Marzorati, 1960: 37-39. Niklison, 32 (Buenos Aires, 31 de julio de 1915): 201-226. Romero, 14/37 (Asunción, 1977): 162-163.

14 Comando General del Ejército, 1974, II, 2: 461-481; La Gaceta Mercantil (Buenos Aires, 1827), 21-31 de diciembre. 
na requirió postes y varillas que los escasos recursos forestales de esa región no alcanzaban a proporcionar en la cantidad necesaria, generándose, así, una demanda de madera chaqueña. Pero las limitaciones de las primeras empresas forestales quedan evidenciadas por el hecho de que la Comisión Exploradora del Chaco, en 1876, halló solamente quince obrajes ubicados en puntos de fácil acceso fluvial y solamente un obraje y aserradero que empleaba a más de cien personas. Todos estos establecimientos estaban ubicados entre los $29 .^{\circ}$ y $26 .^{\circ}$ grados de latidud sur, a lo largo de la costa del río Paraná. Pero los procedimientos de explotación forestal eran totalmente sencillos, no habiendo creado más que un único y precario asentamiento humano en la vieja misión jesuita de San Fernando del Río Negro, no lejos de la desembocadura de este río en el Paraná y no lejos del sitio donde en 1878 fue fundada la ciudad de Resistencia. Ese asentamiento había sido desde hacía muchos años el centro de la explotación forestal, ya que los obrajeros construían allí sus establecimientos principales, exportando las maderas por el llamado puerto de la $\mathrm{Ba}-$ rranquera. Pero muchos de esos establecimientos había sido abandonados, ante los abusos de los empresarios que frecuentemente no pagaban los salarios acordados a los peones - especialmente a los indígenas - lo que había determinado una falta de mano de obra y la consiguiente decadencia de un comercio anual de unos 300.000 pesos fuertes de la época ${ }^{15}$.

A lo largo de la costa del río Paraguay solamente había existido un obraje, el que había sido abandonado ante la hostilidad de los indígenas. En la desembocadura de ese mismo río se estableció, en 1876, Carlos Christiernsson, el que pudo explotar los bosques vecinos tras obtener la colaboración de los indígenas. Esta empresa llegó a tener 17.500 hectáreas en propiedad, con una estancia, San Carlos, un aserradero y un obraje, con unos 150 peones, trescientos bueyes y treinta carros ${ }^{16}$.

$\mathrm{Al}$ alterarse las condiciones que favorecieron su origen, su transformación se hizo evidente: el avance de la frontera determinó su propia liquidación y el obraje debió incorporar una mayor dosis de racionalidad, aun permaneciendo primitivo.

En Misiones, por su parte, como consecuencia del llamado Pacto de la Selva, celebrado en 1874 entre Fructuoso Moraes Dutra y los aborígenes misioneros, se hicieron accesibles a empresarios regiones ricas en bosques silvestres de yerba mate, ilex paraguaiensis, cuya explotación comenzó poco después, pero siendo utilizadas, al principio, solamente las hojas. Las características generales de esos originalmente obrajes yerbateros permite asociar-

\footnotetext{
15 Seelstrang, 1977: 68-69, 73-74, 83.

16 Miranda, 1955: 131.
} 
los, sobre todo en la etapa de su apogeo, a la forma general de los enclaves primitivos, tanto por sus rasgos socio-espaciales como por el hecho de que asumieron un creciente carácter forestal, por la difusión del procedimiento de abatir el árbol a fin de facilitar la recolección de las hojas y por las condiciones de trabajo vigentes en los mismos. Estos obrajes madereros/yerbateros perduraron hasta las primeras décadas del siglo XX, en que fueron implantados, nuevamente, los yerbales de cultivo, creciendo, además, las críticas al sistema laboral imperante en los mismos. Las primeras empresas del Alto Paraná ni siquiera requerían un capital inicial, ya que se exigía a los peones proveerse ellos mismos de los útiles y herramientas de trabajo. De todas maneras la importancia de la producción yerbatera ya había menguado considerablemente en los últimos años del siglo XIX, por cuanto hay elementos de juicio que permiten asegurar que la mitad de la producción considerada nacional era, en realidad, importada de modo clandestino del Paraguay y Brasil ${ }^{17}$.

Las primitivas explotaciones de yerba mate se instalaban donde los descubierteros o conocedores de la selva encontraban manchas de yerbas silvestres, información que vendían a los interesados en extraer el producto. Algo parecido acontecía con la otra forma histórica del enclave misionero, que se implantó para explotar madera, principalmente cedro, lapacho, guatambú, laurel, peteribí e incienso, y era similar a su congénere chaqueño. Los asentamientos madereros y yerbateros estaban vinculados entre sí y con el resto del mundo, en la gran mayoría de los casos, solamente por la vía fluvial. Por el río se desplazaban las provisiones y se despachaba la producción. Un camino principal, la picada maestra, se dirigía hacia el interior de la selva: solía tener más de cinco metros de ancho y una base limpia, para que pudieran desplazarse carros llamados alzaprimas o cachapés, tirados por bueyes o mulas, que llevaban troncos desbastados allí donde había sido derribado el árbol, o vigas, es decir, troncos despojados de corteza y albura. El transporte de la yerba mate se hacía, usualmente, mediante tropas de mulas. A la picada maestra confluían las maestrillas o picadas secundarias, y a estas, los piques, simples caminos peatonales. Solamente en el obraje de la Companía de Tierras y Maderas del Iguazú se había iniciado en 1912 la construcción de un ferrocaril, que en enero de 1913 llegaba al kilómetro 4, pero ya estaban terminadas las obras de desmonte, terraplenes y puentes hasta el kilómetro 14, faltando solamente tender los rieles sobre los durmientes ${ }^{18}$.

17 Niklison, 26 (Buenos Aires, 30 abril de 1914): 23-24.

18 Ibidem: 31. 
Niklison en su trabajo de 1914 relacionado con las condiciones de vida y trabajo en el Alto Paraná encontró 27 obrajes y yerbales sobre la costa argentina ${ }^{19}$.

Los enclaves primitivos misioneros, tanto los madereros como los yerbateros, así como los enclaves primitivos chaqueños, con sus dos variantes, chaqueño-santafesino y santiagueño, tuvieron en común una serie de rasgos que han permitido considerarlos genéricamente.

En una primera etapa, estos establecimientos estuvieron ubicados sobre ambas márgenes del Alto Paraná y sobre una franja costera del Paraná Medio y Paraguay, precediendo, en algunos casos, el corrimiento definitivo de la frontera, pero expandiéndose hacia el interior a medida que se afirmaba el proceso de apropiación de la tierra. En el Chaco Occidental, la instalación de explotaciones forestales acompañó el avance hacia el norte de las líneas ferroviarias, que conectaron los puertos del litorial fluvial con Santiago del Estero, Tucumán y Salta. La apropiación definitiva de la tierra, la conformación de un marco político e institucional que garantizara la difusión de prácticas capitalistas y asegurara, consiguientemente, la legitimidad y el uso de la propiedad privada, y la creciente demanda de productos forestales y de yerba mate, derivados de la expansión de la estancia pampeana, fueron los requisitos para que se afirmara esta forma de organización de la producción.

Originalmente, su instalación se debió a iniciativas de empresarios nacionales y aun locales, asociados más tarde con financistas y comerciantes extraregionales y, en algunos casos, extranjeros. En el Chaco Central, los primeros establecimientos madereros fueron organizados por empresarios provenientes de Asunción, quienes, luego de la federalización del territorio, en 1876, fueron reemplazados por empresarios argentinos y extranjeros. El crecimiento de la demanda de madera dura para diversos usos y de tanino para curtir cueros provocó la expansión de las empresas forestales en toda la región chaqueño-misionera.

Los caracteres generales de estos obrajes madereros/yerbateros se corresponden, en gran medida, a los obrajes primitivos de la frontera, si bien algunos aspectos de las relaciones sociales y de las técnicas de producción, más intensivas en capital, indican cierta modernización. Se mantenían, no obstante, la misma clausura espacial, las mismas formas de coacción económica y extra-económica, constituyendo un nuevo elemento de las mismas la incorporación del ciclo explotativo boliche/bailanta/proveeduría, incluidos —en algunas áreas - los juegos de azar. Las bailantas eran lugares de baile y pros-

19 Ibidem: 31-49. 
tíbulos, en los cuales los futuros peones podían terminar irremediablemente endeudados. Las proveedurías, con un capital inicial, por ejemplo, de 6.000 a 8.000 pesos, obtenían 2.000 pesos mensuales de ganancias y, en 1913, el almacén de un obraje que empleaba 300 obreros y peones, tenía ingresos mensuales que variaban entre 35.000 y 40.000 pesos. Como el pago de los salarios se efectuaba en bonos o vales, los trabajadores se veían obligados a consumir en los negocios establecidos en los obrajes. La única empresa donde se permitía al personal consumir en almacenes y tiendas particulares era en Quebrachales Fusionados S.A., en las proximidades de cuyos establecimientos industriales en Puerto Tirol existían casas particulares como las de Canella Hnos. y Guillermo Dellamea y, además, dicha empresa permitía el comercio independiente dentro de sus propiedades ${ }^{20}$.

Para las explotaciones misioneras los peones se contrataban por un mínimo de seis meses, recibiendo un anticipo de 50 a 100 pesos, para que pudiesen dejar dinero a sus familias y comprar ropa, pero no era raro que buena parte del anticipo se gastara en aquellos negocios en los días previos al embarque. En 1912 existían en Posadas 48 boliches y almacenes al menudeo, de los cuales 20 se encontraban en la zona portuaria, existiendo también en el puerto un sinnúmero de casas de prostitución clandestina, con sus correspondientes despachos de alcohol y baratijas. Los beneficios que redituaban a las empresas tales actividades complementarias podían superar, en algunos casos, a los de la propia explotación maderera. Se mantenían, también, las mismas prácticas depredatorias de los recursos naturales, prácticas agudizadas en Misiones, como ya hemos señalado, por la tendencia a derribar el árbol, y por la ampliación de las áreas de corta. Pero una excepción fue la provincia de Corrientes, en la que se sancionaron normas forestales en 1876 y $1894^{21}$.

\section{EL CICLO DE LA INDUSTRIA DEL TANINO}

El crecimiento de la demanda de elementos estructurales y de materia prima para la elaboración de curtientes generó la expansión de las empresas forestales en todo el ámbito de la región chaqueño-misionera, iniciándose una nueva etapa, la de la explotación continua e intensiva o, empleando otro término, la misma se podría también definir como exhaustiva. Dos fases se sucedieron históricamente en la evolución de las explotaciones forestales cha-

20 Bialet-Massé, 1968: 139; Niklison, 32 (Buenos Aires, 31 de julio de 1915): 97-98; Raffo, 24 (Buenos Aires, 1 de agosto de 1913): 479.

21 Unsain, 26 (Buenos Aires, 30 de abril de 1914): 4. 
queñas maduras, que terminaron integradas bajo la hegemonía de la segunda. La primera fue el obraje, productor primario de madera para durmientes, vigas, postes, varillas, y de subproductos como carbón y leña, o de materia prima para la producción de tanantes naturales. La segunda, la fábrica, más cercana al prototipo de la empresa capitalista decimonónica, aun si se trataba de establecimientos independientes de propietarios argentinos $\mathrm{y}$, más aún, cuando fue transformándose en un segmento de complejas estructuras oligopólicas, como resultado de procesos de acumulación, centralización y movilización de capital, dentro del cual pasó a ejercer un creciente control sobre los obrajes y otras actividades conexas o secundarias, como transporte, comercialización, prestación de servicios urbanos, imponiendo su liderazgo tanto sobre el espacio propio de los establecimientos forestales como en la región.

La integración de las dos fases se puede apreciar con claridad en el Chaco y Santa Fe, en Misiones, en cambio, el proceso no se verificó ni para la explotación yerbatera ni para la maderera. En la variante chaqueño-santafesina la incorporación de la capa fabril se inició en 1889, con la instalación de la primera fábrica de tanino en la localidad correntina de Peguahó, propiedad de la firma alemana Erwig \& Schmidt. Los hermanos Carlos y Federico Portalis, propietarios de la firma Portalis Frères y Cía., obtuvieron en 1879 de la provincia de Santa Fe el derecho de corte de bosques - aproximadamente una decena de leguas cuadradas, es decir, alrededor de 31.000 hectáreas, en la región que rodea la desembocadura de Arroyo del Rey, en las cercanías de Reconquista, limitándose a exportar quebracho a las fábricas de tanino en los Estados Unidos. Pero en 1895 decidieron construir una segunda fábrica de tanino en el pueblo de Five Lilles - actualmente Vera y Pintado- en el norte de Santa Fe. Por su parte, en 1899, los hermanos Carlos y Alberto Harteneck, propietarios de Harteneck y Cía., que hasta ese momento se habían dedicado a la explotación de bosques de quebracho en el norte santafesino, exportándolo a Alemania, pero sin mucho suceso hasta ese momento, decidieron adquirir maquinaria en Amberes para una nueva fábrica no muy lejos de la anterior, en la localidad de Calchaquí, provincia de Santa Fe, en asociación con Carlos Casado, y con una capacidad de producción de 14.000 toneladas anuales de tanino. Los hermanos Harteneck habían adquirido anteriormente la fábrica de Pehuagó. Un año más tarde fue exportado, por primera vez, tanino producido en Argentina ${ }^{22}$.

Estas dos nuevas compañías, estrechamente asociadas con intereses industriales y financieros europeos, y contando ya con arraigo y conexiones en los

22 Bialet-Massé, 1968, 130. Hicks, 1956: 3. Lloyd, 1911: 428. 
medios empresariales de Buenos Aires, además de latifundios en el Chaco, se unieron en 1902, con Hermann Renner, director-gerente de Gerb und Farbstoffwerk H. Renner \& Co Actiengesellschaft, de Hamburgo, empresa dedicada a la producción y comercialización del tanino en Europa, para formar una una nueva compañía, la Compañía Forestal del Chaco, constituida sobre la base de las tierras y fábricas que Portalis y Harteneck ya poseían, y, nuevamente, un año después, en mayo de 1903, fue exportado el primer tanino producido por la nueva compañía ${ }^{23}$.

En los años siguientes esta nueva empresa, que había crecido rápidamente, puso en funcionamiento dos nuevas plantas industriales, ubicadas, también, en el norte santafesino: una en Villa Guillermina, en 1903, con una capacidad de producción de 24.000 toneladas anuales de tanino y esta planta comenzó a funcionar en agosto de 1904 y produjo en los últimos cinco meses de ese año 5.000 toneladas de tanino y, en 1905 produjo 10.553 toneladas; la otra en La Gallareta, en 1906, pero con una menor capacidad de producción, 7.000 toneladas anuales. La fábrica de Calchaquí produjo en 1904, 12.256 toneladas de tanino y, en 1905, 13.292 toneladas. En 1906 producían juntas las plantas de Villa Guillermina y Calchaquí 30.000 toneladas anuales de tanino. La Compañía Forestal del Chaco poseía 516.958 hectáreas, de las cuales 237.338 estaban ubicadas en Santa Fe y 279.620 hectáreas en el entonces territorio nacional del Chaco. Los dividendos que llegó a repartir anualmente entre sus asociados llegaron a un 30\% y nunca fueron inferiores al $9 \%{ }^{24}$.

Ante la creciente demanda internacional del extracto de quebracho, la Compañía Forestal del Chaco, con un capital de 14.000.000 de francos de la época, se vio necesitada de un aumento del mismo, a fin de incrementar la producción. Ante la imposibilidad de conseguirlo en Francia, acudieron a fuentes financieras inglesas ${ }^{25}$. Para ello se reunieron en Londres con el barón Emile Beaumont d'Erlanger, director de la firma Messr. Emile d'Erlanger \& Co., la que se dedicaba a financiar empresas industriales en América del Sur, habiendo sido, por ejemplo, la precursora de la explotación del nitrato en Chile, y asimismo controlaba el Banco Anglo-Sudamericano, que durante muchos años funcionó en Buenos Aires, y que luego fue absorbido por el Banco de Londres y América del Sur. El barón d'Erlanger le solicitó a la firma Gumpert \& Leng, de Buenos Aires, que procediera a una evaluación de las propiedades de la Compañía Forestal del Chaco y de las posibilidades de

\footnotetext{
23 Lloyd, 1911: 426-428. Lütgens, XXV (Hamburgo, 1911): 52-55.

24 The Economist, LXIV, 3270 (Londres, 28 de abril de 1906): 752.

25 Huret, 1913: 311.
} 
expansión de la industria del tanino. El informe de Hilary Leng fue extremadamente favorable, por lo que el barón d'Erlanger decidió inscribir el 26 de marzo de 1906, en el Registro Público de Comercio de Londres, la constitución de The Forestal Land, Timber and Railways Company Limited, con un capital inicial de 1.000.000 de libras esterlinas de la época, capital elevado algunos años más tarde a 1.700 .000 libras esterlinas, dividido en 500.000 acciones de preferencia y 500.000 ordinarias. Pocos días más tarde, el 5 de abril, se firmó un convenio entre la Compañía Forestal del Chaco, Messr. Emile d'Erlanger \& Co. y The Forestal Land, Timber and Railways Company Limited, por el cual le fueron transferidas todas las propiedades de la primera empresa a la nueva empresa: 516.620 hectáreas en propiedad, 275.00 hectáreas de montes en arrendamiento, 160 kilómetros de vías férreas, las fábricas de tanino, en funcionamiento en ese momento, en Villa Guillermina y Calchaquí, maquinarias, locomotras, vagones, barcos, lanchas para el transporte fluvial y los planteles ganaderos ${ }^{26}$.

La asamblea estatutaria de The Forestal Land, Timber and Railways Company Limited se efectuó, en Londres, el 16 de agosto de 1906. Luego de los procedimientos inherentes a la transferencia de las propiedades, se formó el directorio, siendo elegido presidente, Charles Eugene Gunther, que, a su vez, era presidente de Liebig's Extract of Meat Company Limited, propietaria de estancias y frigoríficos en Argentina, Paraguay y Uruguay, entre otros países, y director del Bank of Tarapacá and Argentina Limited. Directores fueron elegidos Emile d'Erlanger, Herbert Edlmann, H.M. Kersey, y los tres directores de la Compañía Forestal del Chaco: Federico Portalis, Alberto Harteneck y Hermann Renner. The Anglo-South American Bank Ltd. y Messr. Emile d'Erlanger \& Co., eran los financistas de la nueva empresa; Messr. Slaughter and May, de Londres, eran los agentes; Deloite, Plender, Griffith and Co., con oficinas en Londres y Buenos Aires, eran los auditores ${ }^{27}$.

En esa misma asamblea se decidió instalar una sucursal en Buenos Aires, denomidada Compañía de Tierras, Maderas y Ferrocarriles La Forestal, Limitada, nombrándose un directorio local, integrado por Adam Mahn, de Messr. Brauss, Mahn and Co.; Víctor Negri, de Portalis Frères y Cía.; Edmund Hermann, de The Pastoril Company, y Charles Moll, de Messr. Moller \& Co. El director general era Richard Petersen ${ }^{28}$.

26 Hicks, 1956: 4-5. Lloyd, 1911: 428, 709-713. Trumper, 1977: 21-27. The Economist, LXIV, 3270 (Londres, 28 de abril de 1906): 752.

27 Hicks, 1956: 5. Lloyd, 1911: 428. Marzorati, 1960: 32-33.

28 Lloyd, 1911: 428. The Economist, LXIV, 3270 (Londres, 28 de abril de 1906): 752. 
La Forestal, en su política de expansión, y con el objetivo de no depender de otras empresas, resolvió constituir en 1907 su propia flota fluvial, formando la Compañía Argentina de Lanchas, independizándose, así, de la Compañía Argentina de Navegación Nicolás Mihanovich, que detentaba hasta ese momento el monopolio del transporte fluvial. El capital de la nueva empresa, que tenía cierta autonomía, fue integrado con accionistas de la empresa principal, pero en 1909 fue incorporada al activo de La Forestal, la que en 1908 compró la totalidad de las acciones de la Compañía El Tanino, Elaboración de Extracto de Quebracho, que tenía una planta industrial en la localidad de El Mocoví, y en julio de ese mismo año adquirió el control de las ventas de la totalidad de la producción, entre 10.000 y 15.000 toneladas anuales de tanino, de Quebrachales Fusionados, monopolizando las ventas durante varios años. En 1910 comenzaron las negociaciones para comprar el Ferrocarril Ocampo - con el que se pretendía en principio formar una compañía aparte- y cuyas vías férreas transportaban la producción del nuevo establecimiento de $\mathrm{La}$ Forestal, ubicado en Villa Ana, hasta Puerto Ocampo, en la costa del río Paraná. La Forestal adquirió en 1913 The Santa Fe Land Company, cuyos dividendos en 1912 habían sido del 12 $\frac{1}{2} \%$, y cuya fábrica de tanino en Santa Felicia fue cerrada y desmantelada al no ser económicamente rentable. Ese mismo año, 1913, fue comprada The Argentine Quebracho Company - cuyas acciones en su totalidad eran poseídas por The New York Tanning Extract Company-, la que se dedicaba fundamentalmente a la explotación del quebracho para la elaboración de tanino, en su fábrica, fundada en 1904, en Tartagal, provincia de Salta; sus propiedades abarcaban 278.487 hectáreas de bosques de quebracho, en las cercanías de la fábrica de Villa Ana, propiedad de La Forestal. También fue comprada Tannin Corporation of New York. En 1921 fue adquirida, debido a una situación financiera desfavorable, la Gerb und Farbstoffwerk H. Renner \& Co. Actengesellschaft y el 51\% del capital de Gebrüder Müller, de Banrath, y un año más tarde la totalidad del capital de la misma; estas dos empresas poseían cuatro fábricas dedicadas a la fabricación de productos del quebracho y pasaron a ser excelentes distribuidoras del tanino argentino en el continente europeo. Así, La Forestal había pasado a controlar el mercado internacional de quebracho y tanino en los Estados Unidos, Gran Bretaña, Europa Central y América del Sur. Pero La Forestal no solamente se dedicaba a explotar quebracho y a producir tanino, sino que, también, destinaba parte de sus tierras a la explotación ganadera, con unas 26.000 cabezas de ganado vacuno. En 1911 la extensión de las vías férreas para el transporte de los productos de La Forestal era de 289 kilómetros, poseyendo, además, 17.000 bueyes de tiro. Ese mismo año fueron vendidas 
una parte de las tierras ubicadas en las cercanías del río Paraná, en parcelas de 50 hectáreas, cuyos precios variaban de 60 a 120 pesos oro por hectárea, pagables a largo plazo $^{29}$.

Esta corporación multinacional llegó a poseer 2.226.177 hectáreas, si sumamos el total de tierras obtenidas por compra y arriendo, llegando a ser un verdadero paradigma de los enclaves forestales, controlando todo el proceso de distribución de la industria taninera en la región chaqueña, tanto por expansión de su propia producción, lograda con la instalación de nuevos establecimientos y la adquisición de otros, como por la compra del tanino elaborado en otras fábricas instaladas en territorio del Paraguay.

\section{LOS CÁRTELES DEL TANINO}

Se puede afirmar que La Forestal fue el eje de un cártel del tanino, monopolizando la producción y la venta de dicho producto en el mercado mundial, y comprando fábricas para clausurarlas o para hacerlas funcionar a su mínima o máxima capacidad de producción, según sus propias necesidades, para de esa manera poder determinar los precios internaciones del extracto de quebracho.

El primer pool, una comunidad de intereses, conocido como Pool de Fabricantes de Extracto de Quebracho, fue organizado por La Forestal el 1 de enero de 1917. Antes de la guerra el desarrollo de la industria del tanino era limitado, ya que algunas fábricas habían tenido que cerrar, al no poder concurrir con Alemania, que compraba quebracho para elaborar tanino en sus propias fábricas. Con el estallido de la guerra desapareció la concurrencia alemana y, además, la industria creció rápidamente ante la demanda internacional y el enorme aumento del precio del producto.

Las siguientes compañías integraban el pool: Quebrachales Fusionados S.A; Las Palmas del Chaco Austral; Compañía Argentina de Quebracho Marca Formosa; Campos y Quebrachales Puerto Sastre S.A.; Compañía de Tierras Carlos Casado Limitada; Sociedad Forestal de Puerto Guaraní; Quebrachales

29 Hicks, 1956: 15-16. Hoar, 1924: 5-8. The Economist, LXV, 3335 (Londres, 27 de julio de 1907): 1278; LXVII, 3385 (Londres, 11 de julio de 1908): 82-83; LXIX, 3438 (July, 17, 1909); LXX, 3485 (Londres, 11 de junio de 1910): 1321; LXXII, 3536 (Londres, 3 de junio de 1911): 1216; LXXIV, 3570 (Londres, 27 de enero de 1912): 153-154; LXXIV, 3591 (Londres, 22 de junio de 1912): 1425; LXXVI, 3626 (Londres, 22 de febrero de 1913): 487-488; LXXVI, 3642 (Londres, 14 de junio de 1913): 1472; Truth, LXIV, 1646 (Londres, 15 de julio de 1908): 160; (Londres, 3 de marzo de 1909): 527-528; 1710 (Londres, 6 de octubre de 1909): 800 . 
y Estancias Puerto Galileo; Atorrasagasti, Piazza y Cía., y Argentine Timber \& Estates Co. Al terminar la guerra de 1914 aumentaron las demandas de madera de quebracho, tanto de Europa como de los Estados Unidos, pero durante la crisis de 1921 el pedido de tanino fue menor, por lo que muchas fábricas tuvieron que cerrar temporariamente, pero un año después creció nuevamente la exportación tanto de durmientes de quebracho como de tanino: en 1921 fueron exportadas 30.857 toneladas de durmientes y 120.100 de tanino, y en 1922 las cifras fueron de 124.822 toneladas y 167.845 , respectivamente. El acuerdo evitaba conflictos por el precio - ya que el mismo era determinado por el cártel - en el periodo de la primera posguerra en que el mercado internacional se reducía y regularizaba la producción. Pero al mismo tiempo obligaba a todas las empresas a limitarse a una cuota rígidamente establecida. Como comprador y vendedor del producto actuaba solamente una firma, Bracht \& Cía., cuyas oficinas estaban situadas en la calle Cangallo 466, en Buenos Aires. El pool se rompió el 31 de diciembre de 1923, por presión de aquellas compañías disconformes con sus respectivas cuotas. Comenzó, entonces, un periodo de guerra de precios y aumento de la producción, parcialmente determinado por la instalación de nuevas fábricas en el Chaco: Noetinger Lepetit S.A., en La Escondida, y la de Francia Argentina S.A., en Resistencia. La política monopolista de La Forestal había despertado recelos en los Estados Unidos, ya que este país era el más grande productor mundial de cueros y el mayor consumidor de quebracho y de tanino, por lo tanto el mantenimiento de esa situación de privilegio dependía de que los precios fueran razonables ${ }^{30}$.

El segundo pool llamado Nuevo Pool o Convenio de Caballeros, existió entre el 1 de marzo de 1926 y julio de 1931; por el mismo se establecía que sobre 366.810 toneladas anuales que se exportaban, 164.210 correspondían a La Forestal. Aparte de La Forestal, las siguientes empresas integraban el pool: Quebrachales Fusionados Sociedad Anónima; Nellen \& Turk; Materias Colorantes; Atorrasagasti, Piazza y Cía.; Compañía de Tierras Carlos Casado Ltda.; Campos y Quebrachales Puerto Sastre; Sociedad Anónima Jalón Limitada; Demetrio Baranda; Compañía Forestal de Puerto Guaraní; Las Mercedes; La Chaqueña; Walter Hinckeldeyn (Samuhi); Francia Argentina S.A.; Josá Femenia; Compañía Noruega Argentina y La Formosa. Adherida parcialmente era Interational Products Company, mientras que las siguientes compañías no formaban parte del mismo: Guillermo Welbers; Enrique Pfahl; Otto Franke (ex Argentine Timber \& Estates Company) y Las Palmas del Chaco

30 Hoar, 1924: 1. 
Austral. Pero la enorme capacidad mecánica de producción, que superaba las 450.000 toneladas anuales, la declinación a partir de 1928 del consumo mundial de cueros y los grandes stocks acumulados, de los cuales solamente La Forestal poseía, directamente o indirectamente, 1.000.000 de toneladas sin vender, fue determinante para que La Forestal decidiera, según un antiguo directivo de la misma, «dar una purga a la industria», bajando los precios un $50 \%$. Muchas compañías no pudieron resistir esa competencia, como Fontana Limitada, Demetrio Baranda, Sociedad Anónima Jalón Limitada, siendo compradas por La Forestal. Otras fábricas, seis en total, debieron cerrar: Sociedad Anónima Quebrachales Dubosc, Enrique Pfahl, Sociedad Anónima Curtiunidas, Sociedad Anónima Compañía Industrial del Yute, Compañía Comercial Noruego Argentina y La Chaqueña S.A. Otras dos empresas, Francia Argentina S.A. y Compañía Productora de Tanino, Atorrasagasti, Piazza y Cía., intentaron subsistir con cierres alternativos de pronunciada duración.

El tercer pool fue organizado por La Forestal en 1934, tras comprar en 1933 a Quebrachales Fusionados S.A., su principal competidora hasta ese momento. Este pool fue integrado por la casi totalidad de los productores de tanino. A principios de la década de 1940 existían en total 22 productores de tanino en Argentina y Paraguay; cinco de esas empresas productoras eran propiedad o estaban controladas por La Forestal, las que producían el 57\% del total del tanino. La Forestal controlaba no solamente la producción de quebracho y tanino sino también su distribución y venta, que se efectuaban a través de los agentes oficiales del pool, por ejemplo, el $70 \%$ del tanino utilizado en los Estados Unidos era importado por la Tannin Corporation, la que desde 1913 era controlada por La Forestal. Este pool existió hasta 1942, cuando se retiraron La Chaqueña S.A., International Product Company / Compañía Internacional y Samuhi S.A. Además ese mismo año comenzaron sus actividades dos nuevas firmas en la provincia de Santiago del Estero: la Sociedad Anónima Weisburd y Cía. y la Compañía Taninera Cotan S.R.L., las que pretendían trabajar fuera del pool. La Forestal respondió consiguiendo que el ministro de Agricultura argentino estableciera en febrero de 1942 un sistema de cuotas de exportación, afirmando de esta manera La Forestal su posición monopólica en el mercado nacional e internacional del quebracho y del tanino. Esta reglamentación del gobierno argentino prevaleció hasta 1960, año en que la industria forestal argentina estaba prácticamente en agonía ${ }^{31}$.

31 Baqué y Begué, 1933: 39-45. Berge, 1944: 112-113. Hicks, 1956: 12-14. Industria (La), 1929: 51-71. Marzorati, 1960: 28-29, 35-39. Miranda, 1955: 147. Romero, 14, 37 (Asunción, enero-abril de 1977): 157-180. 
OTRAS EMPRESAS FORESTALES Y TANINERAS

Existieron, aparte de La Forestal, otras empresas de capitales ingleses, como la Lingham Company of South America, fundada en 1898, y que en 1901 cambió su nombre por el River Plate Timber Company. Esta empresa poseía bosques y un aserradero en el Chaco, pero no pudo crecer y fue disuelta en 1905. The Argentine Timber \& Estates Company fue creada en 1909 con el propósito de comprar 193 millas cuadradas de bosques en la provincia de Jujuy. The Argentine Hardwoods and Land Company, formada en 1910, con un capital inicial de 325.000 libras esterlinas, dividido en acciones de 1 libra, de las cuales 178.000 fueron ofrecidas en suscripción pública, había sido creada con el fin de adquirir 137.000 hectáreas de bosques en el sector chaqueño de las provincias de Jujuy y Salta, junto con líneas ferroviarias propias y planta industrial. El precio de compra fue de 140.000 libras esterlinas, habiendo pagado 93.000 al contado y el resto en acciones. Con la introducción de mejoras pretendían alcanzar una producción anual de madera de 20.000 cargas, lo que les dejaría un beneficio de 60.000 libras esterlinas. Eduardo J. Míguez sostuvo que el costo del transporte de la madera, por ferrocarril, desde esas provincias hasta los centros de consumo en la llanura pampeana parece haber sido demasiado elevado, por lo que dichas empresas no lograron un crecimiento significativo, viéndose obligadas a vender sus propiedades en la década de 1920, luego de sufrir considerables pérdidas ${ }^{32}$.

Otra gran empresa en la región chaqueño-misionera fue Las Palmas del Chaco Austral S.A., propiedad de Carlos y Roberto Hardy, los que tras obtener 20.000 hectáreas en la zona de Solalinde, Chaco, fundaron un ingenio azucarero y simultáneamente comenzaron a explotar los bosques cercanos; posteriormente fabricaron tanino y cultivaron algodón. Su propiedad se extendió más tarde con otras 80.000 hectáreas. En 1909 se constituyó la Sociedad Anónima Las Palmas del Chaco Austral, siendo compradas inmediatamente 7.500 hectáreas a Carlos Christiernsson, en las zonas de Flodorona y San Carlos. En 1915 las actividades industriales de la empresa se basaban en el ingenio azucarero; una refinería de azúcar; una fábrica de extracto de quebracho con capacidad para eleborar 400 toneladas anuales; una fábrica de aceite comestible; una de desmote de algodón; una destilería de alcoholes con una capacidad diaria de 2.000 litros; una curtiembre; un aserradero; talleres para la reparación de locomotoras y vagones; herrería; fábrica eléctrica; fundición; carpintería y seis almacenes destinados a la proveeduría de la pobla126.

32 Míguez, 1985: 178-180; The Economist, LXXI, 3490 (Londres, 16 de julio de 1910): 
ción obrera, estimada por Niklison en unas 3.000 personas, durante los meses de mayor intensidad de los trabajos. Además tuvo dos establecimientos ganaderos, San Carlos y Guaycurú, llegando a tener unas 30.000 cabezas de ganado vacuno. La empresa llegó a poseer un ferrocarril, sistema Decauville, con una extensión total de unos 210 kilómetros. En la década de 1920 la compañía pudo expandirse, con nuevo capital, al incorporarse a la misma la familia Nogués, propietaria de ingenios azucareros en la provincia de Tucumán ${ }^{33}$.

\section{ORganizACIÓN SOCIO-ESPACIAL DE LOS ENCLAVES FORESTALES}

En todos los casos las características socio-espaciales son similares ya que, además de la clausura propia del enclave, este asumió una forma polarizada, es decir, extendiéndose a partir de un centro o polo. En el caso de Misiones, a partir del asentamiento costero se abría la picada maestra, de la cual se desprendían luego maestrillas y piques para conectarla con los campamentos y zonas de explotación ubicadas en las manchas de yerba virgen. En el Chaco, la ubicación no era necesariamente costera pero, de todos modos, muestra los mismos rasgos de precariedad y polarización. Si en Misiones, el río representó siempre la única vía de interconexión hacia la ciudad, en el Chaco ese papel lo cumplió en un primer momento el río, pero en una etapa más avanzada la red ferroviaria, cualquiera fuese el tipo y dimensión de la trocha. La incorporación de la fase fabril en el Chaco incrementó la importancia del enclave, que fue urbanizándose y, por ello, influyó en la evolución de los asentamientos humanos de la región, muchas de cuyas ciudades actuales se remontan a comienzos de ese tipo. En Misiones ese impacto fue casi inexistente pues, debido al carácter altamente polarizado de esa variante, el único centro que tuvo un desarrollo considerable fue Posadas, capital del territorio, que actuaba como centro de distribución y embarque de bienes y personas, así como sede de las empresas o sus sucursales. Los asentamientos costeros fueron subordinados y transitorios, perdurando hasta que se agotaron los recursos de su área de influencia y nunca albergaron actividades ajenas a la de la explotación forestal, como ocurrió en el Chaco.

El advenimiento del ferrocarril con sus líneas conectoras, desvíos industriales y estaciones de carga, proveyó a los obrajes chaqueños y, más aún, a las fábricas de tanino de una red básica de interconexiones. Las estaciones ferroviarias fueron sede de instalaciones fabriles y actividades urbanas, pero

33 García Pulido, 1977: 55-59, 140-145. Niklison, 32 (Buenos Aires, 31 de julio de 1915): 158-173. 
cuando sobrevino la decadencia de la forma de producción que estamos comentando, se produjo también, en muchos casos, el deterioro y desaparición de la mayor parte de esos embrionarios centros urbanos, salvo que pasaran a cumplir un papel espacial distinto, en el marco de la emergencia de otras formas de producción, como ocurrió en algunas áreas de la provincia del Chaco, con la expansión de la pequeña empresa familiar agrícola.

El enclave forestal primitivo fue parte del proceso de expansión económica de un área marginal o excéntrica del territorio argentino, si bien se presentó con características similares en áreas adyacentes del Paraguay y del Brasil. En su forma madura, alcanzó un desarrollo sumamente avanzado para el lugar y la época, y su impacto sobre la organización espacial del nordeste argentino perduró por más de un siglo. Su incorporación a la economía mundial se hizo en forma autónoma, sin la mediación de la economía pampeana, aunque sí a través de los circuitos financieros controlados por el capital europeo.

El enclave forestal maduro resultó de un proceso de acumulación y concentración de capital en manos de algunas empresas oligopólicas, entre las cuales La Forestal actuó en forma casi permanente como un centro de poder aglutinante. Es en la etapa de su apogeo cuando se pueden percibir más claramente las vinculaciones entre el capital financiero, a nivel mundial, y las actividades productivas y prestadoras de servicios ferroviarios y de transporte fluvial, entre otras. Ello demuestra que la asociación entre los establecimientos industriales y las empresas ferroviarias no se limitó al plano técnico, sino que, en gran medida, las decisiones de implantación de las líneas, ramales y desvíos, estuvieron determinadas por los intereses de esos sectores empresarios, los que a su vez pasaron a controlar grandes extensiones de tierras fiscales o privadas.

El control o la influencia sobre el transporte ferroviario acentuó la vigencia de la clausura espacial de los establecimientos forestales, lo que además de contribuir a asegurar la disponibilidad de mano de obra, dificultaba que se infiltraran a potenciales competidores los conocimientos tecnológicos, reforzaba la posición de las proveedurías como abastecedoras monopólicas de empleados y obreros y, finalmente, desalentaba las relaciones con grupos sociales asentados en otras áreas de la región o fuera de esta. Se lograba, así, mantener dentro de las empresas y transformar en dividendos para los accionistas la mayor cantidad posible de beneficios indirectos de la actividad: en términos más técnicos, se obstaculizaba la diseminación de economías externas para mantener las internas. Esas características fueron rasgos esenciales de las explotaciones forestales. La falta de poder real de las autoridades nacionales y provinciales y su permeabilidad a las influencias del poder econó- 
mico y político de las compañías forestales permitieron a estas organizar la vida económica y social de los enclaves según sus propias normas: llegaban, a veces, a administrar justicia en ciertos asuntos y a emitir papel moneda. En las grandes explotaciones forestales terminó habiendo verdaderos pueblos, con servicios industriales, centrales eléctricas, comercios, servicios de transporte, viviendas y otras actividades conexas, en los que no era posible residir ni ejercer el comercio sin acordar los términos con la empresa.

Por último tenemos que la importancia de la mano de obra indígena como mano de obra en la economía regional chaqueño-misionera, al igual que en la economía azucarera de Tucumán, Salta y Santiago del Estero, determinó una política indigenista distinta de la aplicada en las regiones pampeana y patagónica, donde el objetivo básico fue la propiedad de la tierra y no la utilización del indígena como fuerza de trabajo, como en el caso de la región chaqueño-misionera. Ya había sido señalado en 1890 que el futuro de la industria forestal y azucarera en el nordeste argentino residía en la mano de obra indígena barata, ya que los peones provenientes de otras regiones, con sus hábitos, sus necesidades y sus sueldos, no podían competir con los indígenas.

\section{CONCLUSIÓN: LA DECADENCIA DE LAS EMPRESAS FORESTALES}

Entre las causas más importantes de la decadencia de las empresas forestales podemos mencionar: el cambio en las condiciones laborables que se aceleró en la década de 1940, determinado por la legislación y la mayor intervención de los organismos estatales; el tratamiento cambiario aplicado por el gobierno a partir de 1947; los aumentos salariales, por ejemplo, en la asamblea general de accionistas de La Forestal en 1946 se mencionó que los salarios habían alcanzado niveles que la industria forestal no podía seguir soportando; la creación de reservas y parques nacionales y las leyes de reposición obligatoria de especies forestales, pueden haber sido las causas más importantes de la decadencia de las empresas forestales, más aún que 1) el agotamiento relativo de los recursos naturales: en la asamblea general de accionista de La Forestal, celebrado en 1945, se reconocía que aún existían amplios stocks de quebracho en Argentina y 2) el alejamiento gradual de los bosques explotables de las vías de comunicación. Estos últimos fueron factores que influyeron negativamente sobre los costos ya afectados, haciendo que las condiciones de competividad con otros países, como Sudáfrica, Kenia y Rhodesia se redujeran apreciablemente, ya que en esos países La Forestal, a través de sus compañías subsidiarias, como The Natal Tanning Extract Company y 
The Calder and Mersey Extract Company Limited, había extendido sus plantaciones de mimosa y creado nuevas fábricas de tanino. Por su parte en las asambleas de accionistas de 1949 y 1950, el entonces presidente de La Forestal, John B. Sullivan, afirmó que la crisis de la industria del quebracho era temporaria y debida a factores que la empresa no podía controlar, esperando la colaboración de las autoridades argentinas para solucionar la misma. Así se fueron reduciendo apreciablemente los límites económicos de explotación de los bosques y la rentabilidad de las empresas ${ }^{34}$.

El auge de esta forma de explotación forestal tuvo lugar de manera simultánea con el fuerte proceso de desarrollo nacional de principios del siglo veinte, impulsado por la expansión de la agricultura y la ganadería pampeanas, pero en condiciones técnicas, sociales y económicas completamente distintas. El ámbito ocupado por los enclaves forestales había sido destinado originalmente a la formación de colonias agrícolas, para el asentamiento de inmigrantes nacionales y extranjeros. La expansión de dicha forma de organización de la producción impidió ese proyecto por más de medio siglo, y las colonias que lograron instalarse y sobrevivir quedaron alveoladas entre las empresas forestales que ejercían la explotación pecuaria. Durante el periodo 1876-1903, solamente se fundaron dos colonias oficiales en el territorio del Chaco: Resistencia en 1878 y Puerto Bermejo (Timbó) en 1888, con una superficie total de 58.000 hectáreas, contra más de 1.000 .000 de hectáreas entregadas a 29 concesionarios, de un total de 2.500 .000 adjudicadas por el Estado en ese lapso. De las colonias privadas, subsistieron Gandolfi, Benítez, Margarita Belén y Popular. Después de ese periodo la entrega de tierras públicas para la fundación de colonias fue mínima, si exceptuamos los años entre 1904 y 1909, en que se fundaron cuatro, con una superficie total de 643.746 hectáreas, y fundamentalmente entre 1916 y 1921, cuando se repartieron 1.470 .914 hectáreas entre quince colonias.

En Misiones, por su parte, se procedió por una ley provincial de tierras del 22 de junio de 1881 a enajenar más de 2.000 .000 de hectáreas entre 29 beneficiarios, quienes recibieron aproximadamente el $70 \%$ del territorio misionero.

En la provincia de Santiago del Estero fueron vendidas, entre 1898 y 1903 , 3.800.000 hectáreas de monte chaqueño a 48 compradores, que habían constituido ante escribano público, el 23 de julio de 1898, el denominado Sindi-

34 Hicks, 1956, 81-99. The Economist, CXLVIII, 5312 (Londres, 16 de junio de 1945): 829; CL, 5364 (Londres, 15 de junio de 1946): 983; CLIII, 5423 (Londres, 2 de agosto de 1947): 221; CLV, 5472 (Londres, 10 de julio de 1948): 85; CLVII (Londres, 2 de julio de 1949): 47; CLVIII, 5574 (24 de junio de 1950): 1413. 
cato para la adquisición de tierras en Santiago del Estero. El precio que pagaron fue de 0,23 centavos por hectárea, mientras que un durmiente de quebracho, del cual era rica la zona, costaba 1,65 pesos. En el territorio de Formosa solamente se formó una colonia en 1893, con una superficie de 41.360 hectáreas y ubicada en las cercanías de la actual ciudad de Formosa; mientras que la mayor parte del territorio fue repartido entre 14 concesionarios, quienes recibieron 936.730 hectáreas. De la Ley Avellaneda, destinada a poblar los territorios nacionales con colonos europeos que se establecieran como productores agrícolas independientes, poco había quedado. Las grandes propiedades de la región chaqueño-misionera se formaron al amparo de la asfixia financiera de las colonias, al no votar el Congreso los fondos destinados a solventar las necesidades primarias de los potenciales agricultores del territorio misionero.

Pero es necesario reconocer que la apertura del bosque y de la selva originales realizada por las empresas forestales hizo accesibles extensos campos de tierras fiscales a potenciales pobladores, y las estaciones ferroviarias, especialmente las construidas sobre líneas estatales, sirvieron de cabecera de asentamientos rurales en las nuevas tierras. Antes de que existiera un pueblo, la estación ferroviaria - igual que en la región pampeana - ya proporcionaba servicios elementales, que luego se irían ampliando a medida que la población se iba asentando en las tierras fiscales aledañas. La disputa por la tierra entre los distintos sectores, grandes empresas y colonos, se mantuvo latente hasta que las condiciones sociales y políticas nacionales permitieron reactualizar el viejo proyecto colonizador. Su consolidación, al menos en algunas áreas, otorgó una nueva fisonomía al espacio y a la sociedad regional.

\section{BiBLIOGRAFÍA}

Bacqué, Santiago y Begué, Pablo, La industria del extracto de quebracho ante los poderes públicos. Informe presentado a la Comisión Nacional del Extracto de quebracho por los miembros de la misma, representantes de la S. Quebrachales Fusionados, Santiago Bacqué y Pablo Begué, Buenos Aires, Rossi, 1933.

Bialet-Massé, Juan, El estado de las clases sobreras argentinas a comienzos del siglo, Prólogo y notas de Luis A. Despontín, Córdoba. Universidad Nacional de Córdoba, Dirección General de Publicaciones, 1968.

Comando General del Ejército, Dirección de Estudios Históricos, Política seguida con el aborigen, Buenos Aires, Círculo Militar, Biblioteca del Oficial. 1973-1975. 5 vols.: 546, [10]; 341; 570, [21]; 561, [21]; 674, [30]. 
Durland, William D., «The Quebracho Region of Argentina», The Geographical Review, Nueva York, 1924, volume XIV: 227-241.

García Pulido, José, El Gran Chaco y su Imperio Las Palmas, segunda edición, Resistencia, Editó Librería y Papelería Casa García, 1977.

Gullón Abao, Alberto José, La Frontera del Chaco en la Gobernación de Tucumán, 1750-1810, Cádiz, Servicio de Publicaciones, Universidad de Cádiz, 1993.

Hicks, Agnes, The Story of The Forestal, Londres, The Forestal Land, Timber and Railways Company, Limited, 1956.

Hoar, H.M., Tanning Materials Survey. Part II. Quebracho: The Origin and Growth of the Industry and the Significance of its Control to the Leather Industry of the United States, Washington, Government Printing Office, 1924.

Huret, Jules, En Argentine: de Buenos Aires au Gran Chaco, París, BibliothèqueCharpentier, 1913.

«Industria», La Industria Forestal Argentina, Buenos Aires, 1929.

Isabello de Onís, Liliana G., «Régimen laboral del indígena chaqueño», Todo es Historia, Buenos Aires, abril de 1986, Año XVIII, N. ${ }^{\circ} 228$ : 55-65.

Lloyd, Regindald, Twentieth Century Impressions of Argentina. Its History, People, Commerce, Industries, and Resources, Londres, Lloyed's Greater Britain Publishing Company Ltd., 1911.

Lütgens, Rudolf, «Beiträge zur Kenntnis des Quebrachogebiets in Argentin und Paraguay», Mitteilungen der Geographischen Gesellschaft, Hamburgo, L. Friedrichsen \& Co., 1911, Band XXV, Heft 1: 1-7.

Marzorati, Ricardo, La industria del extracto de quebracho en la Argentina, expediente n. ${ }^{\circ}$ 20.003/50: Secretaría de Estado de Industria y Minería, expediente n. ${ }^{\circ}$ 40.226/60: Secretaría de Estado de Comercio, Buenos Aires, 23 de febrero de 1960.

Míguez, Eduardo José, Las tierras de los ingleses en la Argentina, Buenos Aires, Editorial de Belgrano, 1985.

Miranda, Guido, Tres ciclos chaqueños (Crónica histórica regional), Resistencia, Editorial Norte Argentino, 1955.

Niklison, José Elías, «Investigación relacionada con las condiciones de vida y trabajo en el Alto Paraná», Boletín del Departamento Nacional del Trabajo, Buenos Aires, n. ${ }^{\circ}$ 26, 30 de abril de 1914: 15-243.

Niklison, José Elías, «Informe sobre las condiciones de vida y trabajo en los territorios nacionales de Chaco y Formosa», Boletín del Departamento Nacional del Trabajo, Buenos Aires, n. ${ }^{\circ}$ 32, 31 de julio de 1915: 3-195; n. ${ }^{\circ}$ 34, mayo de 1916: 1-235.

Peyret, Alexis, Une visite aux colonies de la République Argentine, París, Imprimerie Typographique de P. Mouillot, 1889. 
Raffo, Sebastián, «Los obrajes del Chaco Austral», Boletín del Departamento Nacional del Trabajo, Buenos Aires, n. ${ }^{\circ} 24,1$ de agosto de 1913: 478-480.

Riet, L. van, «Argentinië. Buenos-Aires. Verslag over 1911», Economische Verslagen van Nederlandse Diplomatieke en Consulaire Ambtenaren, 's-Gravenhage, Zesde Jaargang, 1912-13: 267-369.

Romero, Luis Alberto, «El ciclo del tanino en Argentina», Revista Paraguaya de Sociología, Asunción, enero-abril 1977, año 14, n. ${ }^{\circ}$ 37: 157-180.

Seelstrang, Arturo, Informe de la Comisión Exploradora del Chaco, Buenos Aires, Editorial Universitaria de Buenos Aires, 1971.

Trumper, Miriam, Efectos económicos y poblaciones de la explotación del quebracho colorado: el caso de La Forestal en el Chaco santafesino, Buenos Aires, Instituto Torcuato Di Tella, 1977.

Unsain, Alejandro, «Nota de la inspección elevando a la Presidencia el informe del Inspector Niklison», Buenos Aires, Boletín del Departamento Nacional del Trabajo, Buenos Aires, n. ${ }^{\circ}$ 32, 31 de julio de 1915: III-XV.

Fecha de recepción: 7 de junio de 2010

Fecha de aceptación: 4 de julio de 2011

\section{Creation of a production system: forest enclaves of the Chaco-missionary region (19 ${ }^{\text {th }}$ and $20^{\text {th }}$ centuries)}

The purpose of this paper is to describe the development process of a form of production organization centered on the timber-yerba mate mill and the sawmill-tannin factory. This kind of activity developed in the North East of Argentina during the last decades of the $19^{\text {th }}$ century and the first half of the $20^{\text {th }}$ century. The term enclave is used to designate these hubs of activity with a spatial as well as a socio-economical meaning. They tended to set up a kind of physical isolation or spatial enclosure. These enclaves spread out on lands that had been recently appropriated to the indigenous communities. There they built up a territorial domain to which they gave a certain configuration that changed as the conditions of the original form of production organization developed.

KEY WORDS: form of production organization; enclave; spatial enclosure; territorial domain. 